\title{
LXXXVI. Remarks on Dr. Read's paper on refraction
}

\section{Mr. Charles Stark}

To cite this article: Mr. Charles Stark (1821) LXXXVI. Remarks on Dr. Read's paper on refraction, Philosophical Magazine Series 1, 58:284, 431-433, DOI: 10.1080/14786442108652655

To link to this article: http://dx.doi.org/10.1080/14786442108652655

曲 Published online: 27 Jul 2009.

Submit your article to this journal

LII Article views: 2

Q View related articles $\sqsubset$ 
can be no doubt that the specimens now in the Museum were in a much better state when they were first discovered; and the most perfect even, and those the coarsest in their texture, must have been greatly injured during the 69 years that they have been exposed to the atmosphere. I found that a fragment of a brown MS. kept for a few weeks in a portion of air confined by mercury, had caused the disappearance of a considerible part of the oxygen, and the formation of much carbonic acid.

LXXXVI. Remarks on Dr. ReADE's Paper on Refraction. By Mr. Charles Stark, of Portsmouth.

\section{To Dr. Tilloch.}

Sir, - I $I_{N}$ the Number of your Magazine for October, I observe a paper by Dr. Reade, on the subject of Refraction, wherein a very determined attempt seems to be made to overturn the whole doctrine of Dioptrics, and to explain all the phænomena of optics on the principle of reflection alone. If he should really succeed in the accomplishment of this design (which he seems to anticipate with no small degree of confidence), an important æra will, no'doubt, be formed in the history of science, and an inevitable death blow given to those standard works on the subject, which have been so long adopted in our schools and miversities. How far the Doctor is likely to succeed in effecting such a revolution, is my object here to inquire.

In the formation of any new theory, or in the determination of a general law in philosophy, such as the one under consideration, it may be presumed that the author, before publishing it to the world, would have observed the utmost degree of caution, not only in establishing the reasonableness of the hypothesis itself, but also in submitting it to the test of repeated and varied experiments, so as to be found not only consistent with itself, but successful in all its applications. In this respect, no theory has ever been employed, in any department of Natural Philosophy, with more complete success than that which Dr. R. is here endeavouring to explode. In reviewing the arguments, however, which he has brought forward in its refutation, and also those advanced in support of his own, it will require but little ingenuity of reasoning to show that his time and labour have been spent to very little purpose.

Dr. R. commences his paper by endeavouring to refute the expianation that is usually given of the common optical experiment of placing a piece of money at the bottom of an empty vessel, and its seeming to rise higher as water is poured into it. He objects to the common explamation by saying: "How can 
any bending of the rays of light bring the object mearer to the eye ?" A satisfactory demonstration of the reason why it should appear so, may be found in almost every clementary treatise on optics; but from what he expresses in the next passage, it appears that it would require something else than either mathematical or ocular demonstration to satisfy him. "If," says he, "s we bend a piece of iron wire, we certainly shorten the length it extended; but if the rays of light were so bent, they would fall short of the object!" What Dr. R.'s opinions may be of the manner in which light is transmitted, is not easy to guess; but I should suppose them to be quite as original as some of his other views : at all events, he certainly cannot suppose that it is either by a continued stream of particles from the luminous body, or by an agitation of the intervening medium, or he could never talk of comparing the rays of light to pieces of wire, or any other substance, of a determinate length. It therefore appears that his objection proceeds entirely from sone peculiar metaphysical notions of the nature of light, and not from any absurdity which he can demonstrate to exist in either the reasoning or results of the old doctrine; and should he olnose to communicate those ideas, we may have an opportunity of combating hin with his own weapons.

But let us now proceed to what follows, where he pretends to have demonstrated by experiment the identity of reflection and refraction. The passage which it will be necessary to quote, is as follows :

"Having placed a piece of money at the bottom of a wineglass, I made the edge of it intercept my view; on pouring in a small quantity of water, the shilling seemed to rise; I now perceived two inages of the object, one at the bottom, and the other foating at the top of the water, very apparent when the glass was a little inclined to the eve. This floating image was agitated by every movement of the water. To ascertain whether this image was the real cause of vision, I held the glass above my eye, and saw the image floating by reflection on the surface of the water as if reflected from the face of a mirror. Further to convince myself that it is this floating image we see, and not the shilling at the bottom of the vessel, I brought my eye on a line with the image, and then gently lowering the glass, at the same time keeping my eye intently fixed on it, I saw the image by transmitted rays."

It happens rather unfortumately for Dr. R.'s doctrine, that this experiment, on which the whole of it is founded, is, of all others that he could possibly have hit upon, the best calculated to expose its absurdity. If he had only observed, in making the experiment, that whou the glass was slightly shaken so as î agitate 
the surface of the water, the reflected image that was seen when the glass was placed above, would appear quite confused and indistinct, on account of the great dispersion of the reflected rays, while the other seen with the glass held below the eye would be comparatively little affected. Now this, which is explained in the most satisfactory manner by the laws of reflection and refraction, is quite irreconcileable with Dr. R.'s hypothesis ; and it would be easy to point out abundance of other examples where it is equally inconsistent. What Dr. R. has observed with regard to the appearances of the two images, is nothing more than one of the many analogical relations that may be observed betweer the laws of refraction and reflection, but furnishes not the slightest proof of their identity.

As to what follows in the remaining part of the paper, it is merely an extension of the same principle which he deduces from the above experiment : consequently I do not, at present, consider it entitled to any further consideration.

$$
\text { I am, sir, }
$$

Your most obedient servant,

Portsmouth, Nov. 13, 1821 .

Cha. StakK.

LXXXVII. Thoughts on the Cultivation of Maize as a green Crop, to come in late in the Summer and Autumn. By A Praitical and Experimental Farmer.

$I_{\mathrm{r}}$ is only in particular seasons, and in favourable situations, that Indian corn or Maize is ever known to ripen its seed in this climate, except by artificial means : every attempt, therefore, to naturalize and cultivate it, so as to produce a profitable crop of grain, will, it is to be feared, prove abortive. There is one purpose, however, for which we have reason to believe that its cultivation might be adopted by the English farmer, especially the cottage farmer, and with considerable advantages. I mean as an article of green food, in the place of spring tares or buckwheat. There are few annual plants of such rapid and luxuriant growth, and none by which it is exceeded, the sugar-cane excepted, in nutritious properties. So much, indeed, does it abound with saccharine matter, that it is no very uncommon practice, as 1 have been informed, in some parts of America to extract sugar from it. There are, it seems, several varieties of this plant, differing in the colour of the seed, their times of ripening, and in the luxuriance of their growth. It is unnecessary to say, that for the purpose for which it is here suggested, the last property ought certainly to be preferred, unless, indeed, it is slower in coming to maturity than the other varieties. The price of maize

Vol. 58. No.284. Dec. 1821 . 3 I in 